\title{
UV assisted electrochemical technologies for the removal of oxyfluorfen from soil washing
}

wastes

\author{
E. Vieira dos Santos ${ }^{1}$, C. Sáez ${ }^{2}$, P. Cañizares ${ }^{2}$, C.A.Martínez-Huitle ${ }^{3}$, M.A. Rodrigo ${ }^{2, *}$ \\ ${ }^{1}$ School of Science and Technology, Federal University of Rio Grande do Norte, Campus \\ Universitario, 59078-970 Natal, Brazil \\ ${ }^{2}$ Department of Chemical Engineering, Enrique Costa Building, Campus Universitario s/n, 13071 \\ Ciudad Real, Spain \\ ${ }^{3}$ Institute of Chemistry, Federal University of Rio Grande do Norte, Campus Universitario, 59078- \\ 970 Natal, Brazil
}

\begin{abstract}
In this work, it is studied the treatment of soil polluted with oxyfluorfen by Surfactant-aided SoilWashing (SASW) and after that, photo-electrolysis was used for the treatment of the soil-washing fluid produced. This liquid waste is characterized by the high concentration of micelles of pesticide and surfactant (sodium dodecyl sulfate, SDS), whose initial size depends on the ratio soil-surfactant used in the soil washing treatment. The waste treatment is studied in terms of the decrease in size of the particles and the depletion of the pollutants. Results clearly demonstrate that photo-electrolysis with diamond electrodes is a very effective treatment technology with results that overcome those obtained by single photolysis and/or single electrolysis with diamond electrodes. The greater improvements attained by combining UV irradiation to the electrolysis were observed in the removal of the pesticide while the removal of the surfactant was little affected. Electrolysis does not only deplete the complete concentration of pesticide but it also shows to be very efficient in the depletion of the surfactant, preventing its potential recycle. The significant concentration of sulfate released during the attack to the surfactant and the effect of the peroxosulfate anions that are formed from the anodic oxidation of that anion, explain the improved performance of the technology in the treatment of washing fluids with higher concentrations of SDS.
\end{abstract}


Keywords: Oxyfluorfen, photolysis, photo-electrolysis, soil washing, Boron Doped Diamond, electrolysis

\section{Highlights}

- Photo-electrolysis can mineralize completely soil washing fluids

- Photolysis only produces a very soft oxidation of soil washing fluids

- Mineralization of oxyfluorfen by electrolysis is improved with UV irradiation

- Mineralization of SDS by electrolysis is almost not affected by the UV irradiation

- Sulfate released by the oxidation of SDS catalyses photo-electrolysis

*author to whom all correspondence should be sent: manuel.rodrigo@uclm.es 


\section{Introduction}

Over the last years, the search for novel sources of water has become a topic of the major interest, in particular in countries with serious problems of permanent or stationary lack of water. Global warming is definitively contributing to make the problem even greater and hence, to increase the necessity of developing solutions to this serious problem. Consequently, the development of novel and efficient technologies capable to remove complex pollutants and provide water of high quality, from wastewater, is not only a topic of the major interest nowadays; but for sure it will be the target of significant research in the next years. Unfortunately, we are far away from the development of an efficient treatment technology, robust enough to transform wastewater into high quality water and this fact explains the huge interest paid by the scientific community to Advanced Oxidation Processes in the recent years [1-3]. Among those technologies, electrolysis with diamond anodes has received considerable interest for the removal of very different types of pollutants in the recent years [4-9] because of its outstanding efficiency, explained in terms of the combination of direct (by electron transfer) and mediated (through the formation of oxidizing/reducing agents at the electrode) oxidation approaches $[8,10]$. In particular, the formation of highly powerful oxidants from the salts contained in wastewater seems to be one to the clear advantages of the diamond electrolytic technologies [11] and, hence, the role of not only hypochlorite but also that of peroxocarbonates, peroxophosphates, peroxosulfates, hydrogen peroxide and ozone is important in order to explain the high efficiency of these technologies. To improve the performance of the processes, the activation of these reagents is a process of the major importance. The final aim is to produce species that can enable the rapid degradation of the pollutant species. Three important aspects should be taken into account: (i) the dosage of the precursor for the production of oxidants (i.e., $\mathrm{Cl}^{-}, \mathrm{SO}_{4}{ }^{2-}, \mathrm{CO}_{3}{ }^{2-}$ etc, ), but preferentially it should be contained in wastewater to avoid the undesired salinization of the waste, (ii) the oxidant produced on the electrodes should be efficient for the oxidation of pollutant contained in wastewater, (iii) 
sometimes, the oxidant produced is not active for the oxidation of the pollutant but it could be activated.

Activation of oxidants, that is, the formation of highly reactive species from poorly reactive oxidants [12], can be attained by combination of oxidants or by UV light or ultrasounds irradiation [13-15]. Among them, the irradiation of UV light seems to be particularly promising [16-18] and photolytic treatments may be used for generation of oxidant species and also for the direct dissociation of organic pollutants through a radiation source. The irradiation of UV light is attained with lamps and among the different sources of radiation, mercury vapour lamps are widely used, because of their low cost, ease of operation, good energy efficiency (proportion of electrical power converted into radiation) and good spectral efficiency (proportion of radiation emitted as UV)[19].

Recent research has pointed to the use of combined processes because it takes advantage not only of the good features of the single technologies but also that of their potential synergistic effects. This fact has been confirmed during the treatment of many types of pollutants, such as dyes [20, 21], pharmaceuticals [16, 22], pesticides [14, 23, 24], plasticizers [25], carboxylic acids [26], phenol [27] and surfactants [19]. In those works, it was found that in addition to the well-known UV light based processes; combination with electrochemical technology allows the formation of powerful radicals during the treatment [28-30] as indicated in eqs 1 to 4.

$$
\begin{aligned}
& \mathrm{H}_{2} \mathrm{O}_{2}+h v \rightarrow 2^{\bullet} \mathrm{OH} \\
& \mathrm{H}_{2} \mathrm{O}+\mathrm{O}_{3}+h v \rightarrow 2^{\bullet} \mathrm{OH}+\mathrm{O}_{2} \\
& \mathrm{~S}_{2} \mathrm{O}_{8}^{2-}+h v \rightarrow 2\left(\mathrm{SO}_{4}^{-}\right)^{\bullet} \\
& \mathrm{ClO}^{-}+h v \rightarrow \mathrm{O}^{-\bullet}+\mathrm{Cl}^{\bullet}
\end{aligned}
$$

A clear example of this synergistic combination was described in the literature [27], by studying the well-known mineralization of phenol in the presence of chloride. After $6 \mathrm{~h}$ of treatment, photolysis resulted in $29 \%$ phenol mineralization and electrochemical treatment resulted in $35 \%$ and $52 \%$ mineralization using $\mathrm{BDD}$ and ruthenium oxide on titanium $\left(\mathrm{DSA}-\mathrm{Cl}_{2}\right)$ anodes, respectively. After the same treatment period, the photo-assisted electrochemical process removed 
$88 \%$ and $96 \%$ of total organic carbon (TOC) by using BDD and DSA- $\mathrm{Cl}_{2}$ anodes, showing clearly a synergistic combination.

Taking into account this background, the objective of this study is to investigate the remediation of soils polluted with oxyfluorfen (Figure 1) by a combined treatment consisting of the surfactant-aided soil washing (SASW) with a sodium dodecyl sulfate (SDS) solution followed by the photolysis and/or photo-electrolysis with conductive-diamond anodes of the soil-washing fluid.

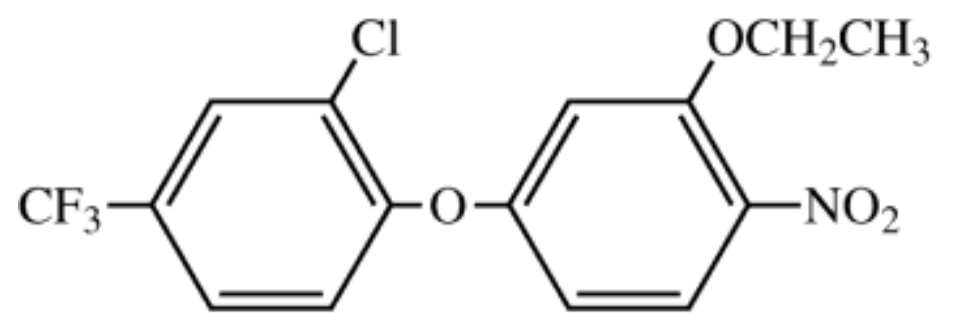

Fig. 1. Chemical formula of oxyfluorfen.

The resulting soil-washing fluid is a complex wastewater characterized by the presence of soluble pollutants, micelles of pesticide and surfactant. An important point is that no additional salts were added to improve the treatment performance but just the salts contained in the raw soilwashing fluid. Hence, this work not only focus on the interest of the removal of this pollutant (development of the environmental remediation technology) but also (and very important) in the treatment of colloids-containing wastewater, trying to give significant insights about the treatment of this type of complex wastes.

\section{Materials and methods}

Chemicals. Oxyfluorfen (2-chloro-1-(3-ethoxy-4-nitrophenony)-4-(trifluoromethyl), 99.8\% purity benzene, HPLC-grade acetonitrile, ethyl acetate and hexane were obtained from Sigma-Aldrich (Spain). Sodium dodecyl sulphate (SDS) (used as solubilizing agent) and sodium hydrogen 
carbonate $\left(\mathrm{NaHCO}_{3}\right)$ were obtained from Panreac. Deionized water (Millipore Milli-Q system) was used to prepare all solutions.

Analytical techniques. The oxyfluorfen concentration in the liquid phase was determined using a Liquid-Liquid extraction process. This process was carried out in separator flasks of $100 \mathrm{~cm}^{3}$ using ethyl acetate/hexane as extraction solvent (ratio oxyfluorfen solution/solvent $=0.52 \mathrm{v} / \mathrm{v}$ ). All samples extracted from electrolyzed solution were filtered with $0.25 \mu \mathrm{m}$ nylon Whatman filters before analysis. The concentrations of the compounds were quantified by HPLC (Agilent 1100 series) using analytical column Phenomenex Gemini $5 \mu \mathrm{m} \mathrm{C18}$. The detection wavelength of 220 $\mathrm{nm}$ was used and the temperature oven was kept at $25^{\circ} \mathrm{C} .20 \mu \mathrm{L}$ aliquots were injected, using as mobile phase, a mixture of acetonitrile/water $(70: 30(\mathrm{v} / \mathrm{v}))$ at $0.3 \mathrm{~cm}^{3} \mathrm{~min}^{-1}$. TOC concentration was monitored using a Multi N/C 3100 Analytik Jena analyser. The oxyfluorfen and surfactant removals were monitored through the COD content during electrolysis using a HACH DR2000 analyser. Zeta potential was also measured for the clarified liquid using a Zetasizer Nano ZS (Malvern, UK). Measurements of $\mathrm{pH}$ were carried out with an InoLab WTW pH-meter. The particle size was monitored during electrochemical oxidation with a Mastersizerhydro 2000SM (Malvern). The colorimetric method used to determine the concentration of the SDS surfactant has been reported elsewhere [31]. The anions present in the target wastewater were characterized using ion chromatography by means of a Shimadzu LC-20A system.

Preparation of spiked soil. The procedure used to pollute the soil consisted on the solubilisation of oxyfluorfen in acetonitrile; after that, a mixture between oxyfluorfen/acetonitrile solution with kaolinite was obtained. The spiked clay was aerated for 1 day to favour evaporation of the acetonitrile. In this way, the oxyfluorfen was homogeneously distributed into the clay surface. The concentration of oxyfluorfen contained in the soil was fixed about $100 \mathrm{mg} \mathrm{kg}^{-1}$. 
Preparation of the soil washing fluid. Soil washing with surfactant fluid solution was carried out in a stirred tank operated in discontinuous mode. The tank volume was $1000 \mathrm{~cm}^{3}$. Low-permeability soil (1000 g) polluted with $100 \mathrm{mg}$ of oxyfluorfen in $1 \mathrm{~kg}$ of soil by using $800 \mathrm{~cm}^{3}$ of solubilizing agent (containing deionized water, $500 \mathrm{mg} \mathrm{dm}^{-3}$ of $\mathrm{NaHCO}_{3}$ ) and different concentrations of sodium dodecyl sulphate (SDS) surfactant ranging from 100 to $5000 \mathrm{mg} \mathrm{dm}^{-3}$ were mixed in the reactor for $6 \mathrm{~h}$ at a stirring rate of $120 \mathrm{rpm}$. The same tank then acted as a settler (during $24 \mathrm{~h}$ ) to separate the soil from the effluent. These effluents consisted of complex aqueous mixtures of oxyfluorfen, surfactant and sodium hydrogen carbonate, with emulsified micro drops and soluble species, which become the influent of the electrolytic treatment. It is important to remark that, $\mathrm{NaHCO}_{3}$ was included in the preparation of soil washing in order to avoid significant variations of $\mathrm{pH}$ conditions during its treatment by photolysis and photo-electrolysis processes. Meanwhile, SDS was selected as surfactant agent because it is frequently used in this studies and it is of easy acquisition.

Photolysis and photo-electrolysis. Two different degradation techniques were employed as follows: photolysis (interaction of UV radiation and electrode surface), (b) photo-electrolysis (simultaneous application of a constant current and UV radiation). A UV lamp VL-215MC (Vilber Lourmat with $\lambda=254 \mathrm{~nm}$, intensity of $930 \mathrm{~W} / \mathrm{cm}^{2}$ and energy $4.43-6.20 \mathrm{eV}$ ) was used to irradiate $15 \mathrm{~W}$ directly to the quartz cover. Electrochemical oxidation experiments were carried out in a bench-scale plant with a single-compartment flow cell. BDD and steel electrodes were used as anode and cathode, respectively. Characteristic of $\mathrm{BDD}$ are as follows: $\mathrm{sp}^{3} / \mathrm{sp}^{2}$ ratio: 225 ; boron content: 500 ppm; width of the diamond layer: $2.68 \mu \mathrm{m}$. For the electrochemical flow cell, inlet and outlet were provided for effluent circulation through the reactor; the SASW effluent was stored in a thermo-regulated glass tank $\left(1000 \mathrm{~cm}^{3}\right)$ and circulated through the cell using a peristaltic pump at a flow rate of $200 \mathrm{dm}^{3} \mathrm{~h}^{-1}$. The electrical current was applied using a DC Power Supply (FA-376 PROMAX). Temperature was kept constant by means of a water bath. The initial conductivity of 
the effluents generated during the soil washing at different SDS concentrations (from 100 to 5000 $\mathrm{mg} \mathrm{dm}{ }^{-3}$ ), ranging from $368 \mu \mathrm{S} / \mathrm{cm}$ to $122 \mathrm{mS} / \mathrm{cm}$. Profiles of concentrations were obtained by sampling solutions at predetermined time intervals during the electrolysis process (robustness of the results was evaluated by four independent analyses).

\section{Results and Discussions}

The soil-washing process by using surfactant is an ex situ process that improves the removal of contaminants sorbed to soil [32], enhancing the contact between extracting agents and soil pollutants, thereby allowing better transference of the pesticide from the soil matrix into a simpler and easier liquid phase to be treated. In the case of pesticides with a low solubility, the washing fluid dosed should contain surfactants, being SDS one of the most commonly used because of the typically high efficiencies attained and its low hazardousness. Figure 2 shows the changes in the turbidity during the photo-electrolysis of the five soil-washing fluids polluted with oxyfluorfen obtained after the treatment of the soil with different concentrations of surfactant SDS (from 100 to $5000 \mathrm{mg} \mathrm{dm}^{-3}$ ). Turbidity is an indirect measurement of the total concentration of colloids contained in a dispersion and hence its change informs about how colloids concentration is affected by the treatment. It is important to take into account that due to the insolubility of oxyfluorfen in water, SAWS drags the pesticide by forming micelles in which the organic chain of the SDS face the pesticide while the sulfonyl groups face the water. As can be observed in Fig. 2, at the initial point of the photo-electrolysis (no electric charge still passed), the lower the concentration of SDS used to extract pesticide from soil, the lower is the resulting turbidity, indicating that the concentration of micelles is also lower. Regarding the electrochemical remediation technology, the concentration of colloids is completely depleted during the treatment, achieving higher removal efficiencies when higher levels of initial turbidity are attained, because depletion of turbidity was obtained almost for the same time and current charge applied $\left(\approx 25 \mathrm{kAh} \mathrm{m}^{-3}\right)$. This behavior was observed even despite 
the initial turbidity contained in the five washing fluids varied within the broad range 200-900 NTU for the different SDS doses applied.

Another feature is the effect of single photolysis on the soil-washing fluids with the highest and lowest surfactant concentration (see Fig. 2). A very slow change is observed (as compared to that obtained in the photo-electrolysis), suggesting that photochemical processes plays a key role on turbidity, although scarcely important in comparison to that of the photo-electrolysis technology.

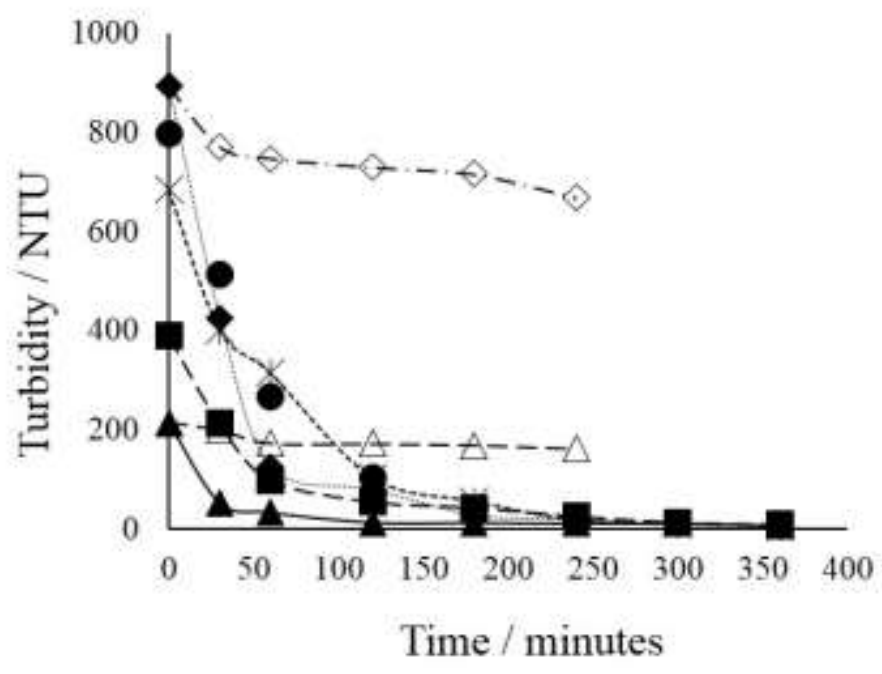

Fig. 2. Turbidity profiles during the photolytic (empty symbols) and photo-electrolytic (full symbols) treatments of soil-washing fluids obtained with SDS concentrations of $(\boldsymbol{\Delta}, \triangle) 100,(\boldsymbol{\square})$ 500, (×) 1000, (•) 2500 and $(\diamond, \diamond) 5000 \mathrm{mg} \mathrm{dm}^{-3}$. [Oxyfluorfen $]_{0}=100 \mathrm{mg} \mathrm{dm}^{-3}$.

Figures $3 a$ (high particle size) and $3 b$ (low particle size) show the decrease in the particle size during the photo-electrolysis treatment of the five washing fluids containing oxyfluorfen. As it can be observed, regardless of the initial micelles mean-size, there is a rapid decrease in the size of micelles, down to the detection limits of the equipment used. This observation is in total agreement to the behavior observed for the turbidity (see Fig. 2), indicating that, higher micelle size is present in solution, higher turbidity values are achieved. Another important point is that initial size of 
micelles depends on the ratio SDS/pesticide. The lower the SDS concentration used in the soilwashing process $\left(100 \mathrm{mg} \mathrm{dm}^{-3}\right)$, the higher is the resulting micelle size. This behavior was previously reported for the soil washing of atrazine [33], although in that case, the sizes of the resulting micelles were completely different. Low SDS-containing soil-washing fluids lead to a lower amount of bigger micelles while high SDS washing fluids lead to higher concentrations of smaller colloids. Hence, despite having the same reactants (pesticide and surfactant), the resulting soil-washing fluids are completely different and it is reflected on a different reactivity (even in that related to the change in size of the micelles size).

On the other hand, as previously indicated, poor efficiencies were obtained when the single photolysis approach was used in comparison with photo-electrolysis process; although some reactivity is observed, with a decrease in the mean size of particles as a function of the irradiation time (see Fig. 3 (empty symbols)). This behavior was consistent with the changes observed for turbidity (Fig. 2), indicating that single photolysis is also attacking the micelles.
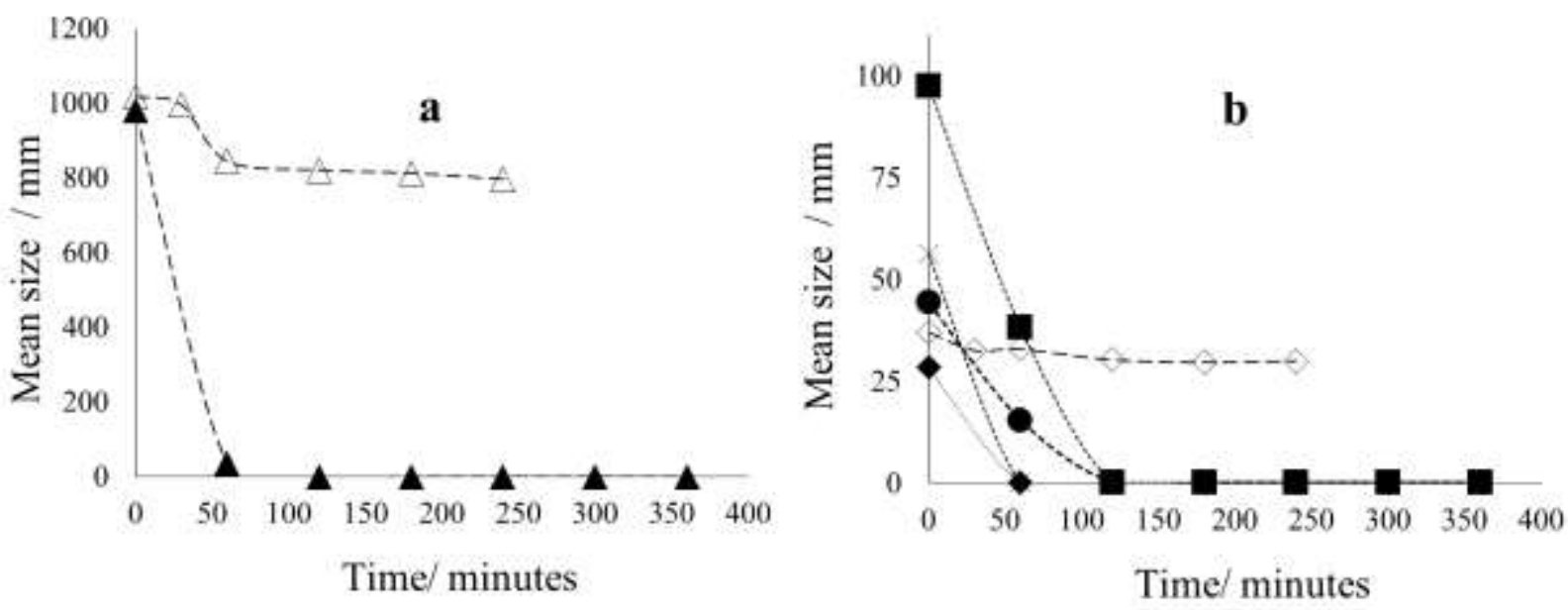

Fig. 3. Mean size particle profiles during the photolytic (empty symbols) and photo-electrolytic (full symbols) treatments of soil-washing fluids obtained with different SDS concentrations. a) $(\boldsymbol{\Delta}, \triangle) 100$ and b) (ロ) 500, (×) 1000, (•) 2500 and $(\diamond, \diamond) 5000 \mathrm{mg} \mathrm{dm}^{-3}$. [Oxyfluorfen $]_{0}=100 \mathrm{mg}$ $\mathrm{dm}^{-3}$. 
In comparing these changes with those observed in an electrolysis with no UV irradiation (Fig. 4), it can be concluded that the change of size is much higher when wastewater undergoes light irradiation, indicating that some different processes associated with photolysis occur in the bulk, in addition to the electrochemical processes. Likewise, the small changes observed during the single photolysis (shown in Figure 3) indicates that the improvement obtained during the photoelectrolysis is not simply explained by the addition of the two single processes, but a synergistic effect caused by the combination of treatments could be attained. A last important observation, from these results, is that the size diminution seems to be related to the initial size of the micelles (which is inversely related to the SDS concentration added) and it increases with it (please pay attention to the logarithmic scale).

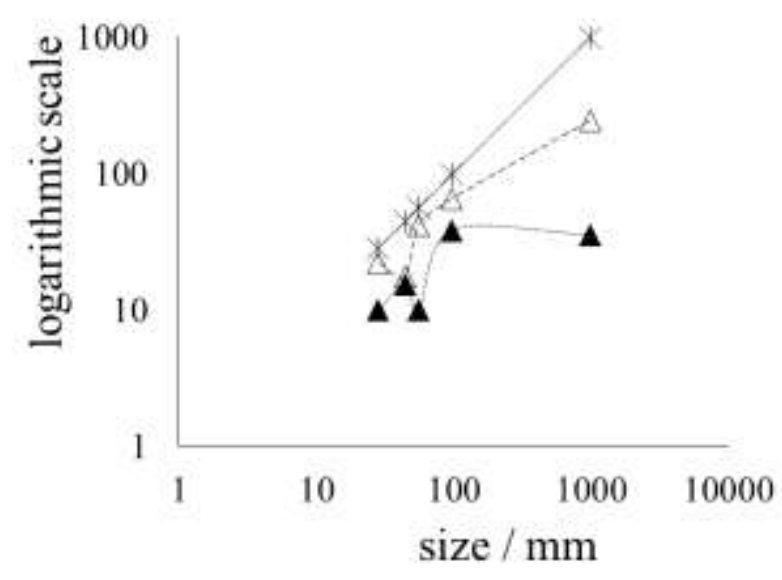

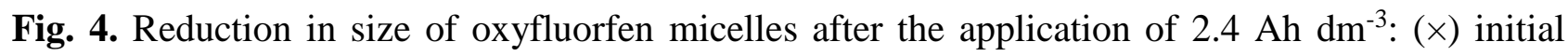
size, $(\boldsymbol{\Delta})$ photo-electrolysis and $(\triangle)$ single electrolysis).

Changes in size of pesticide-surfactant micelles should lead to changes in the micelles surface and these should be reflected on their charge. To understand these effects, the measurements of zpotential were performed (Fig. 5), because as it is known, z-potential informs about the surface charge of these micelles. As it can be seen in Figure 5, initial z-potential of micelles depends on the 
size of micelles: the lower the size, the higher is the resulting z-potential, indicating that more negative charges associated to the sulfonic group of the SDS are covering the surface. During the treatment, the charge of largest micelles becomes more negative as the size decreases, while in the case of the smallest micelles the trend is just the opposite, and they become less negatively charged as the size is decreased. In this case, in order to explain this behavior it should be taken into account that sulfonic groups are forming a protective core of the micelles and they are easily destroyed leading to the dissolution of sulfate in the electrolyte. The release of sulfate was confirmed by the detection of this ion by ion chromatography and it is clearly observed in Figure 6, for both processes (photolytic and photo-electrolytic). Obviously, and in accordance to previous observations, it is much more important in the photo-electrolytic technology because of the higher extension of the remediation reactions. The destruction of the SDS may explain the increase in the value of the z-potential up to less negative values. Anyhow, at the end of the test, when no appreciable micelles concentration is observed by the zetasizer analyzer, the value tends to nearly $50 \mathrm{mV}$, which is associated with the values under the detection limit of the particles measuring equipment.

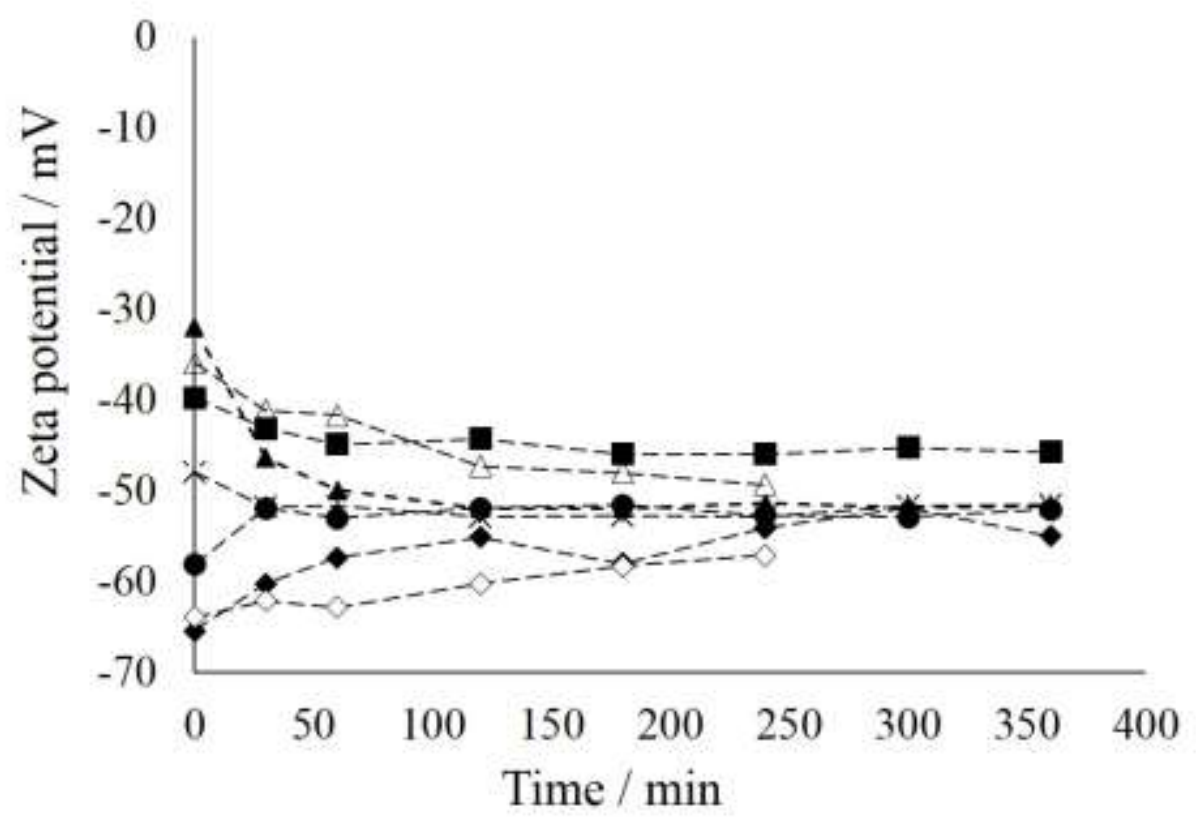


Fig. 5. Zeta potential profiles during photolytic (empty symbols) and photo-electrolytic (full symbols) treatments of soil-washing fluids obtained with different SDS concentrations: $(\boldsymbol{\Lambda}, \triangle)$ 100, (ロ) 500, (×) 1000, (•) 2500 and $(\diamond, \diamond) 5000 \mathrm{mg} \mathrm{dm}^{-3}$. [Oxyfluorfen] $]_{0}=100 \mathrm{mg} \mathrm{dm}^{-3}$.

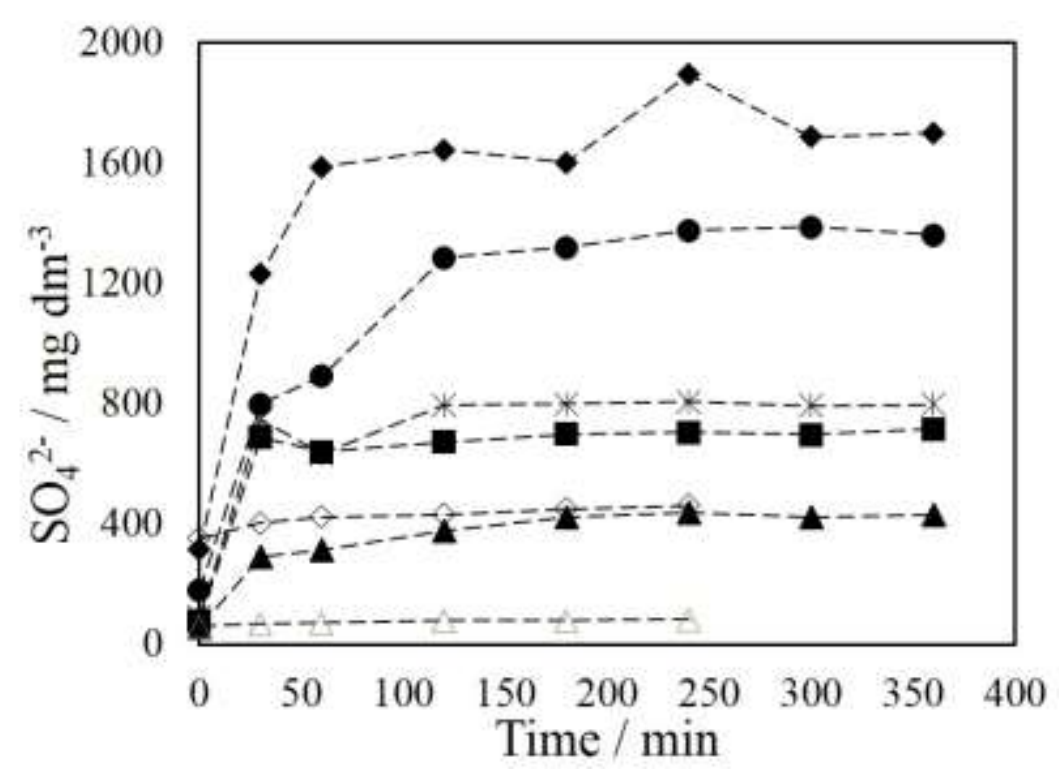

Fig. 6. Changes during the CDEO of surfactant-soil-washing effluent concentration of $\mathrm{SO}_{4}{ }^{2-}$ during the photolytic (empty symbols) and photo-electrolytic (full symbols) treatments of soil-washing fluids obtained with different SDS concentrations: $(\boldsymbol{\Delta}, \triangle)$ 100, (घ) 500, (×) 1000, (•) 2500 and $(\diamond, \diamond) 5000 \mathrm{mg} \mathrm{dm}^{-3}$. [Oxyfluorfen $]_{0}=100 \mathrm{mg} \mathrm{dm}^{-3}$.

In comparing values with those obtained when no UV irradiation is applied during the electrolysis (Figure 7) it can be observed that light did not affect to the surface charge of micelles (despite having a great influence on the size decreasing rate), because the value obtained after applying the same electric current charge is nearly the same, despite the very different initial values of the soilwashing fluid fed to the treatments. This is very important, especially if it is taken into account the very different initial values and it indicates that the same characteristics for the treated wastes were observed, after the treatment. 


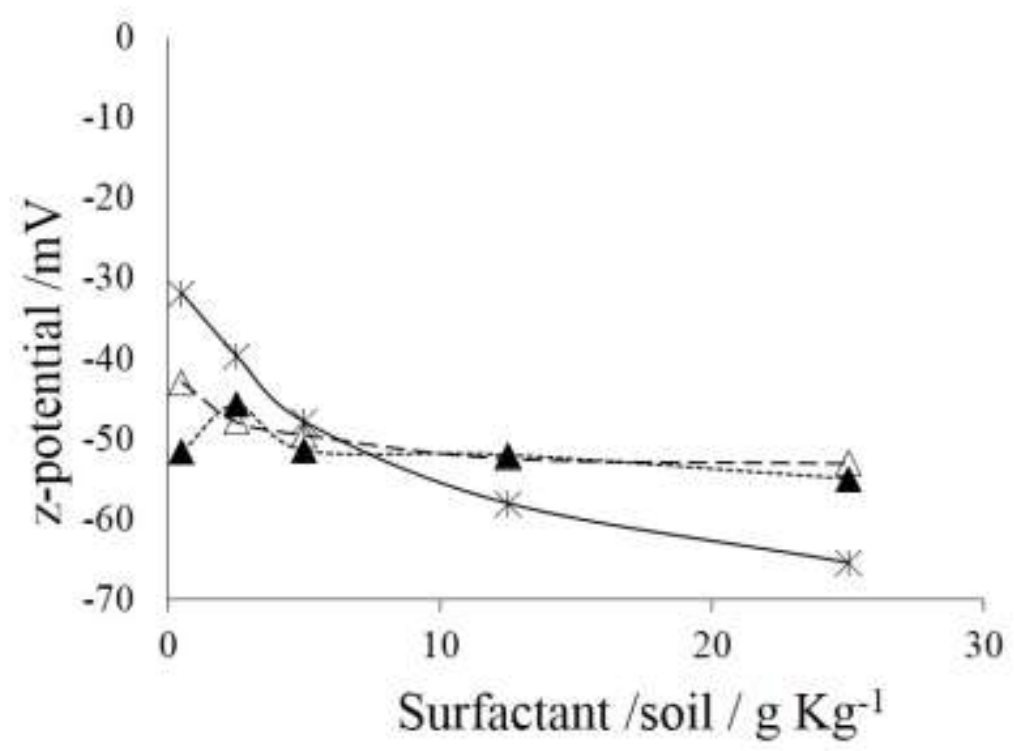

Fig. 7. z-potential of the raw soil-washing fluid and of the effluent of the electrolysis and photoelectrolysis after the application of $7.3 \mathrm{Ah} \mathrm{dm}^{-3}(\times$ initial value, $(\mathbf{\Delta})$ photo-electrolysis and $(\triangle)$ single electrolysis).

Hence, photo-electrolysis of soil-washing fluids polluted with pesticides proceeds through the attack to the colloids and it leads to a progressive decrease in the size of the particles. Once the particles and their changes during the treatments have been described; it is important to focus on the main chemical species contained in the waste: the pesticide and the surfactant. Figure 8a shows the time-course of the concentration of oxyfluorfen during photolysis and photo-electrolysis tests. Pesticide is depleted for current charges applied over $25 \mathrm{Ah} \mathrm{dm}^{-3}$ by photo-electrolysis approach, regardless of the concentration of surfactant in the washing fluid used for the soil washing process. However, the depletion rate at photo-electrolysis seems to be related to the characteristics of the washing fluid and the higher the SDS concentration (or the lower the initial mean size of the particles) the higher is the depletion rate. As shown in Figure 8b, in comparing results with those 
obtained when no UV light is irradiated, a huge difference is observed. This difference becomes greater for larger micelles and hence the efficiency observed for the degradation of oxyfluorfen in the washing fluid, with largest particle is more than double when the fluid undergoes UV light irradiation. Contrary, the difference becomes negligible in the treatment of effluents containing the smallest micelles (that at the same time contain the higher concentrations of SDS).
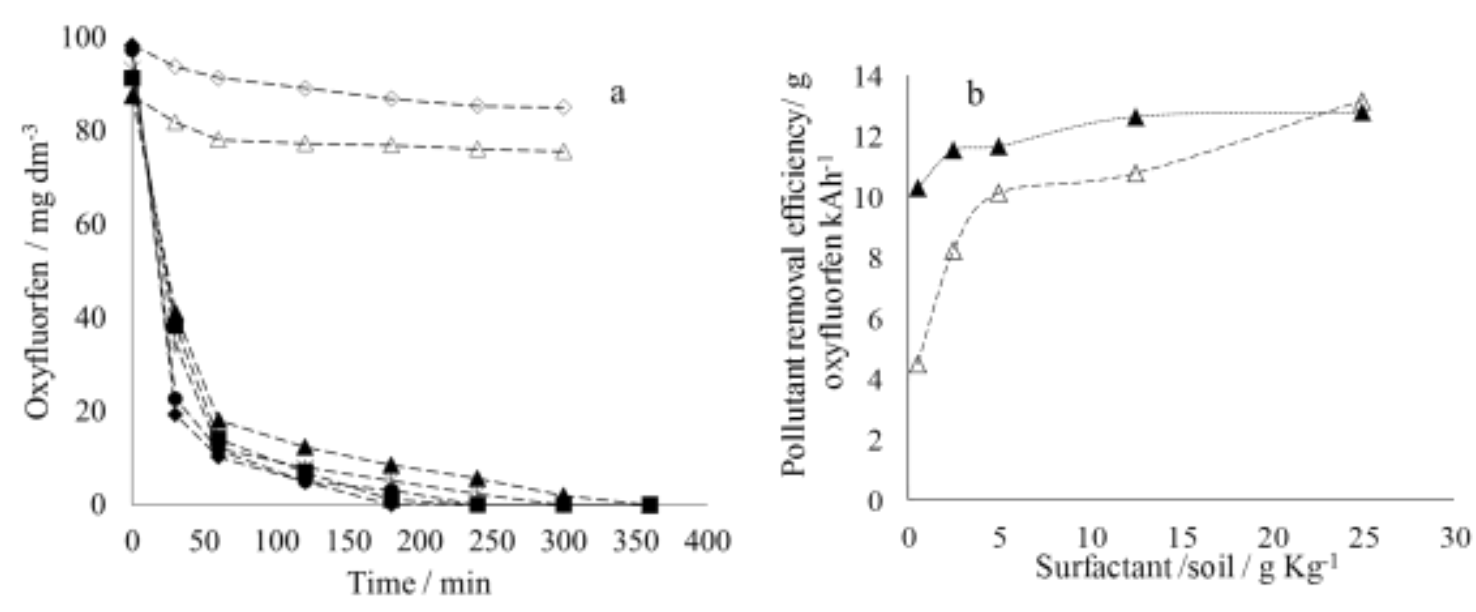

Fig. 8. a) Oxyfluorfen removal profiles during the photolytic (empty symbols) and photoelectrolytic (full symbols) treatments of soil-washing fluids obtained with different concentration

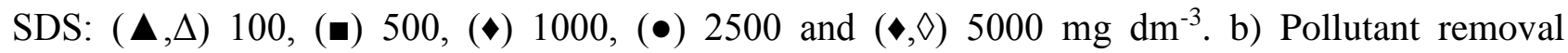
efficiency obtained after passing 7.3 $\mathrm{Ah} \mathrm{dm}^{-3}$ : ( $\left.\mathbf{\Delta}\right)$ photo-electrolysis and $(\triangle)$ single electrolysis. $[\text { Oxyfluorfen }]_{0}=100 \mathrm{mg} \mathrm{dm}^{-3}$.

The significant differences observed between electrolytic and photo-electrolytic processes for the removal of pesticide oxyfluorfen are not observed for the depletion of the surfactant but only a slight improvement for large concentration of SDS. As it is shown in Figure 9, SDS is depleted during the treatment, regardless the initial concentration contained. From the viewpoint of the treatment of the soil-washing fluid, this is a very interesting result, because it clearly indicates that SDS is not refractory to the treatment. However, this result also informs that the recycling of SDS 
cannot be attained with this technology. This observation was pointed out, before, in other previous SASW works. Oxidizability of SDS was previously studied by our group both in single solutions and in complex wastes [34-36] and it was found to be efficient, regardless of the complex structure of the SDS which is made up of a large hydrocarbon chain which should be difficult to remove by other AOPs. In comparing the effect of irradiating UV light, improvements observed are around $10 \%$. This fact means that photo irradiation is more effective for improving the electrolysis of the aromatic pesticide than the elimination of the aliphatic surfactant and it is important because although the oxidazability of organics using diamond anodes is very robust and can attain the complete mineralization of all organic tested according to the literature [1, 3], a clear difference is found in this work. Likewise, mechanisms that explain the effect of UV irradiation are the activation of oxidants such as peroxosulphates, peroxocarbonates, hydrogen peroxide and ozone. The improvement observed, confirms the role of these mechanisms and the higher effect for higher SDS ratios for which more sulfate are release pointed out this significance.
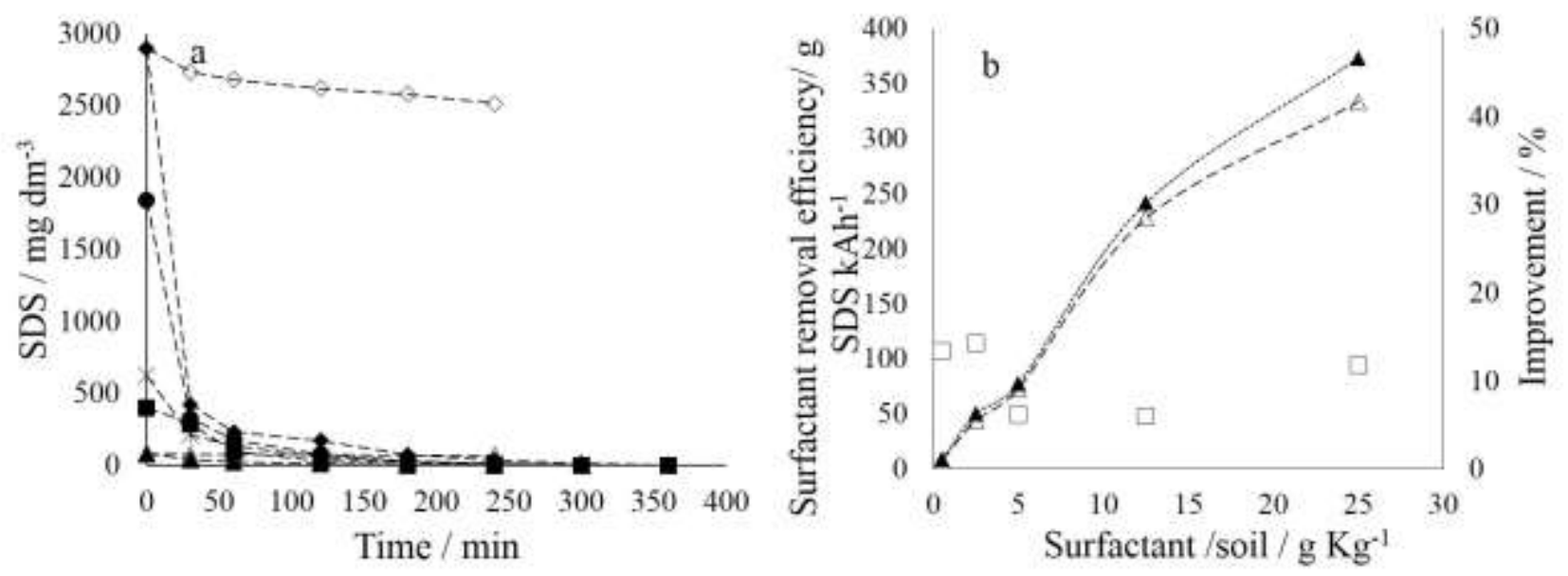

Fig. 9. a) SDS removal profiles during the photolytic (empty symbols) and photo-electrolytic (full symbols) treatments of soil-washing fluids obtained with different SDS concentrations: $(\boldsymbol{\Lambda}, \triangle) 100$, (घ) 500, (×) 1000, (•) 2500 and $(\diamond, \diamond) 5000 \mathrm{mg} \mathrm{dm}^{-3}$. b) SDS removal efficiency obtained after 
passing 7.3 Ah $\mathrm{dm}^{-3}$ : ( $\left.\mathbf{\Delta}\right)$ photo-electrolysis, ( $\triangle$ ) single electrolysis, ( $\square$ ) improvement of irradiating UV light. [Oxyfluorfen $]_{0}=100 \mathrm{mg} \mathrm{dm}^{-3}$.

The good performances in terms of efficiency obtained in the treatment of washing fluids with high concentrations of SDS may be related to the higher amounts of sulfate released. These higher concentrations were shown in Figure 6. Based on the existing literature, the occurrence of phosphate, carbonate or sulfate anions in a waste undergoing electrolysis with diamond leads to the formation of peroxocompounds, such as peroxophosphates $[37,38]$, peroxosulphates $[39,40]$ and peroxocarbonates [41]. All these species act in a similar way: they are known to be good oxidants but its effect on organic compounds is dramatically increased when they are activated through the formation of radicals such as the phosphate, sulfate or carbonate radicals [42]. However, peroxocarbonates are difficult to synthesis, and similar to many other oxidants, and it is favored at low current densities, at high concentrations of carbonates in the raw materials and when using divided cells. Therefore, the larger concentration of sulfates produced during the treatment indicates also a greater concentration of these species and hence explains the higher efficiency of the treatment when the raw soil-washing fluid contains higher concentration of SDS. It also explains that decay of pesticide and surfactant fits better to a straight line rather than to an exponential shape, because the concentration of sulfates (and hence that of potential pesulfates) increases during the treatment helping to prevent the decay in the rate caused by the lower concentration of organics to be oxidized during the treatment. Regarding the differences in the reactivity of pesticide and surfactant when UV light is irradiated, it may be explained because of the higher reactivity of the sulfate radicals with aromatic species. Peroxosulfates are known to be activated by light to sulfate radicals, which are much harsher oxidants than the parent non-radicalary compounds (Eq. 3). However this radical reagent is not very efficient with aliphatic chains. This explains that light irradiation leads to a clear improvement in the case of the removal of pesticide while it almost does not affect to the removal of SDS [43]. 
Changes observed for the two organic species contained in the raw soil-washing fluids reflects on the changes of parameters typically used to monitor pollution of a waste (TOC and COD) as it is shown in Figures 10 and 11. Hence, only slight differences are observed in the TOC removal rate while irradiating UV light and these changes become higher in the case of COD due to the higher influence of the pesticide in this latter measurement. Anyhow, total mineralization is attained indicating that no refractory species are formed during the photo-electrolysis treatment and its strong relation with the concentration of the surfactant and pesticide indicates that effect of intermediates is almost nil.
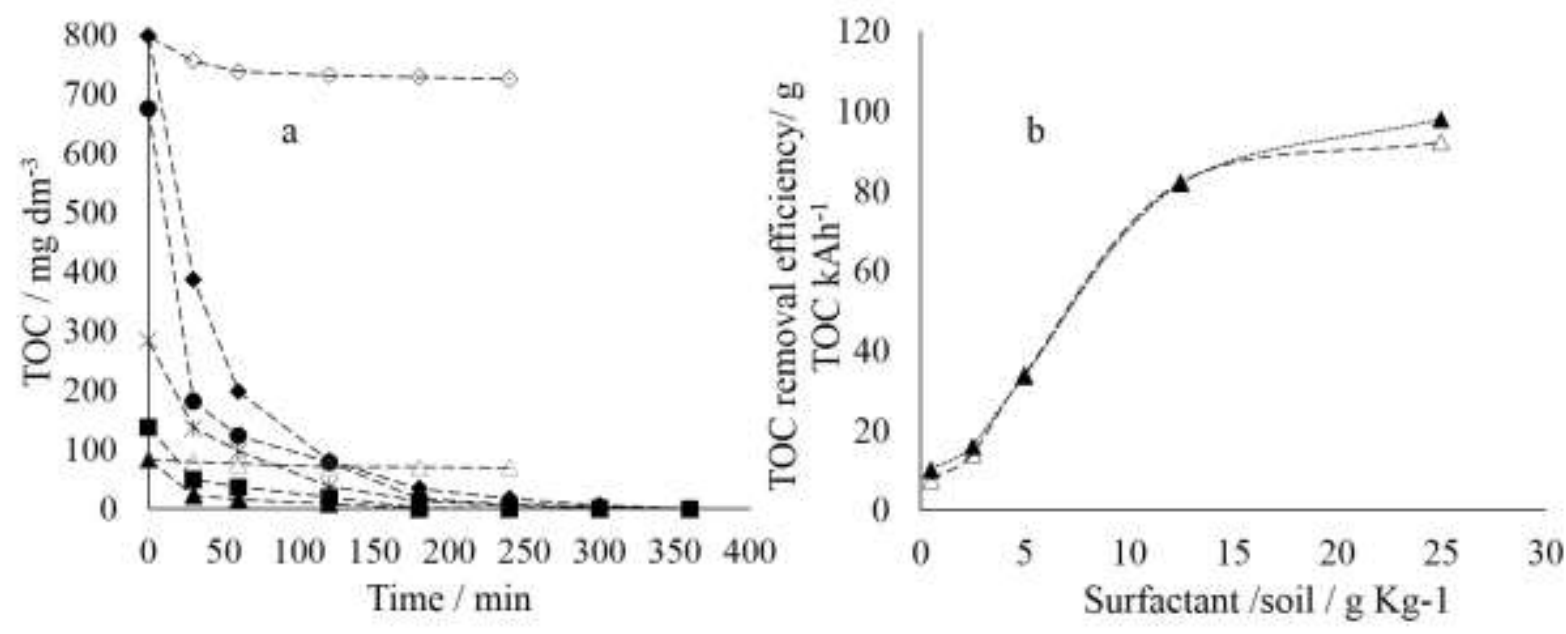

Fig. 10. TOC removal profiles during the photolytic (empty symbols) and photo-electrolytic (full symbols) treatments of soil-washing fluids obtained with different SDS concentrations: $(\boldsymbol{\Delta}, \triangle)$ 100, (匹) 500, (×) 1000, (•) 2500 and $(\bullet, \diamond) 5000 \mathrm{mg} \mathrm{dm}^{-3}$. [Oxyfluorfen $]_{0}=100 \mathrm{mg} \mathrm{dm}^{-3}$. 

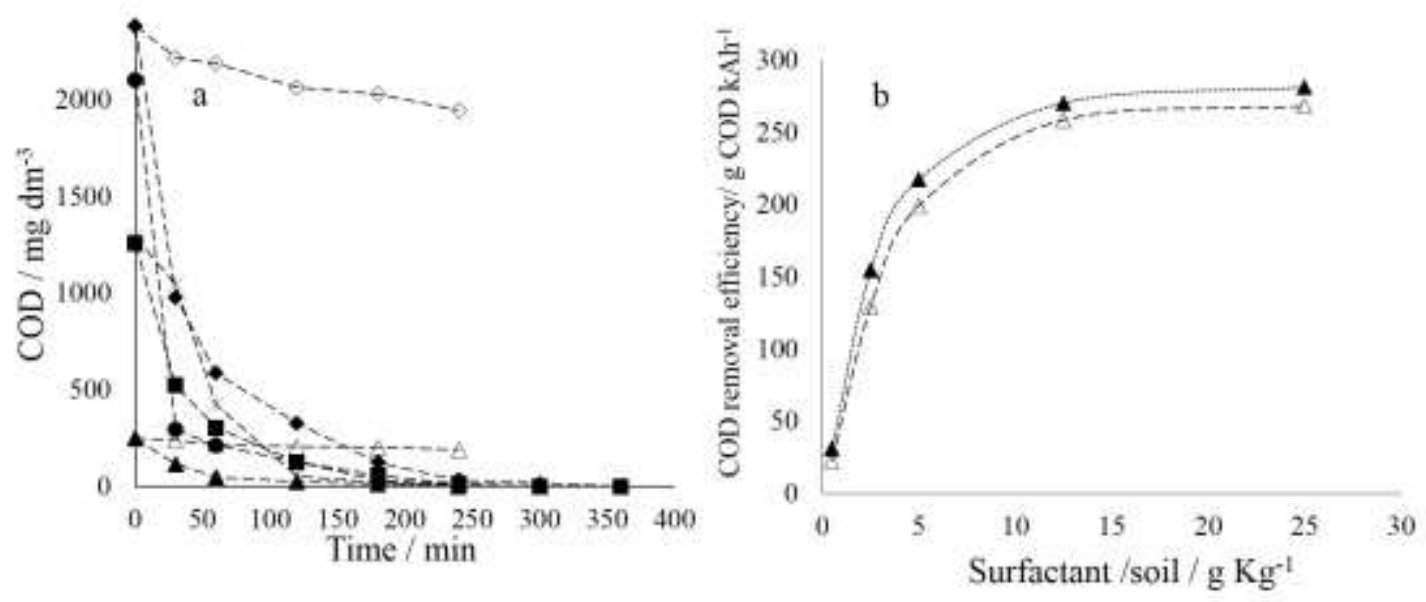

Fig. 11. COD removal profiles during the photolytic (empty symbols) and photo-electrolytic (full symbols) treatments of soil-washing fluids obtained with different SDS concentrations: $(\boldsymbol{\Delta}, \triangle) 100$, (•) 500,(*) 1000, (•) 2500 and $(\diamond, \diamond) 5000 \mathrm{mg} \mathrm{dm}^{-3}$. [Oxyfluorfen] $]_{0}=100 \mathrm{mg} \mathrm{dm}^{-3}$.

In fact, the process is very harsh and almost no intermediates are found in the reaction media by HPLC. Lower areas were detected at two retention times (3.7 and $9.0 \mathrm{~min})$ as a function of SDS concentration. Likewise the maximum concentration detected does not follow a pattern suggesting that once the oxidants attack the colloids, the degradation of the molecules is almost complete and more important than the oxidation of raw molecules contained in the micelles.

Hence, combination of SASW with photo-electrolysis attains a very efficient treatment for the removal of non-soluble pesticides from soil. The treatment of the soil-washing fluids proceeds through the attack to the micelles and after that, the SDS or the oxyfluorfen molecules are started to be oxidized, the oxidation is focused on intermediates rather than in other new pesticide or surfactant molecules and intermediates measured are almost nil. The significance of the mediated electrochemical oxidation processes is pointed out by the high influence of the SDS concentration (understood as precursor of sulfate and hence of peroxosulfate) and by the different effects on the 
oxidizability of the pesticide and the surfactant observed when UV light is irradiated, that can be explained by the preferential attack of the sulfate radicals to aromatic molecules.

\section{Conclusions}

From this work, the following conclusions can be drawn:

- Surfactant-Aided Soil-Washing can be efficiently used to remove oxyfluorfen contained in soil and transfer it to a soil washing fluid. The characteristic of the washing fluid depends strongly on the dose of surfactant used. The lower the surfactant concentration used, the greater are the micelles formed. Likewise the higher the surfactant concentration, the more negative is the z-potential of the resulting micelles.

- Photo-electrolysis with diamond electrodes is a very efficient technology for the removal of oxyfluorfen and SDS from soil washing fluid. In comparing the UV irradiated technology with the single electrolysis, it was observed a clear improvement in the removal of pesticide and almost nil effect on the removal of the SDS.

- During the oxidation of SDS significant amounts of sulfate are released. The catalytic effect of the peroxosulfate produced electrodically helps to understand better the process and explain the higher depletion rate observed in the experiments in which the SDS concentration of the washing fluid was higher.

- Photolysis attains a very soft oxidation of the micelles. The addition of the effects of photolysis and electrolysis is below the observed for the combination of the technologies in a single stage. This means that photo-electrolysis is a synergistic technology.

- Only two intermediates (and in very low concentrations) were obtained during the treatment. This observation means that once the micelles are attacked, the surfactant and pesticide release are rapidly mineralized.

Further experiments are in progress in order to evaluate other surfactant agents (e.g.: betacyclodextrin or Twin 80 because these are preferably used compared to ionic surfactants due to 
their lower soil sorption ability, higher solubilization capacity and higher cost-effectiveness $[32,44])$, dosage and different electrochemical advanced oxidation processes for treating soil washing fluids [13].

\section{Acknowledgements}

The authors acknowledge funding support from the EU and Spanish Government through the MINECO Project CTM2013-45612-R, FEDER 2007-2013 PP201010 (Planta Piloto de Estación de Estación de Regeneración de Aguas Depuradas) and INNOCAMPUS. C. A. Martínez-Huitle thanks funding from the National Council for Scientific and Technological Development (CNPq 446846/2014-7 and CNPq- 401519/2014-7, Brazil). E.V. dos Santos also thanks for PhD fellowship given for "doutorado sanduiche" under "Ciências sem Fronteiras" program to develop the experimental research at the UCLM-Spain.

\section{References}

[1] I. Sirés, E. Brillas, M.A. Oturan, M.A. Rodrigo, M. Panizza, Electrochemical advanced oxidation processes: today and tomorrow. A review, Environmental Science and Pollution Research, (2014).

[2] C. Barrera-Diaz, P. Canizares, F.J. Fernandez, R. Natividad, M.A. Rodrigo, Electrochemical Advanced Oxidation Processes: An Overview of the Current Applications to Actual Industrial Effluents, Journal of the Mexican Chemical Society, 58 (2014) 256-275.

[3] M.A. Rodrigo, N. Oturan, M.A. Oturan, Electrochemically Assisted Remediation of Pesticides in Soils and Water: A Review, Chemical Reviews, 114 (2014) 8720-8745.

[4] M.A. Rodrigo, P. Canizares, A. Sanchez-Carretero, C. Saez, Use of conductive-diamond electrochemical oxidation for wastewater treatment, Catalysis Today, 151 (2010) 173-177.

[5] E. Brillas, C.A. Martínez-Huitle, Decontamination of wastewaters containing synthetic organic dyes by electrochemical methods. An updated review, Applied Catalysis B: Environmental, 166167 (2015) 603-643.

[6] C.A. Martinez-Huitle, E. Brillas, Decontamination of wastewaters containing synthetic organic dyes by electrochemical methods: A general review, Applied Catalysis B-Environmental, 87 (2009) 105-145.

[7] M. Panizza, G. Cerisola, Application of diamond electrodes to electrochemical processes, Electrochimica Acta, 51 (2005) 191-199.

[8] M. Panizza, G. Cerisola, Direct And Mediated Anodic Oxidation of Organic Pollutants, Chemical Reviews, 109 (2009) 6541-6569.

[9] E.V. dos Santos, S.F.M. Sena, D.R. da Silva, S. Ferro, A. De Battisti, C.A. Martínez-Huitle, Scale-up of electrochemical oxidation system for treatment of produced water generated by Brazilian petrochemical industry, Environmental Science and Pollution Research, (2014). 
[10] O. Simond, V. Schaller, C. Comninellis, Theoretical model for the anodic oxidation of organics on metal oxide electrodes, Electrochimica Acta, 42 (1997) 2009-2012.

[11] P. Canizares, C. Saez, A. Sanchez-Carretero, M.A. Rodrigo, Synthesis of novel oxidants by electrochemical technology, Journal of Applied Electrochemistry, 39 (2009) 2143-2149.

[12] F.L. Souza, C. Saez, P. Canizares, A.J. Motheo, M.A. Rodrigo, Coupling photo and sono technologies to improve efficiencies in conductive diamond electrochemical oxidation, Applied Catalysis B-Environmental, 144 (2014) 121-128.

[13] C. A. Martínez-Huitle, M. A. Rodrigo, I. Sires, O. Scialdone, Single and Coupled Electrochemical Processes and Reactors for the Abatement of Organic Water Pollutants: A Critical Review. Chem. Rev. 115 (2015) 13362-13407.

[14] F.L. Souza, C. Saez, M.R.V. Lanza, P. Canizares, M.A. Rodrigo, Removal of pesticide 2,4-D by conductive-diamond photoelectrochemical oxidation, Applied Catalysis B-Environmental, 180 (2016) 733-739.

[15] D.M. de Araujo, C. Saez, C.A. Martinez-Huitle, P. Canizares, M.A. Rodrigo, Influence of mediated processes on the removal of Rhodamine with conductive-diamond electrochemical oxidation, Applied Catalysis B-Environmental, 166 (2015) 454-459.

[16] M.J. Martin de Vidales, S. Barba, C. Saez, P. Canizares, M.A. Rodrigo, Coupling ultraviolet light and ultrasound irradiation with Conductive-Diamond Electrochemical Oxidation for the removal of progesterone, Electrochimica Acta, 140 (2014) 20-26.

[17] M.J. Martin de Vidales, C. Saez, J.F. Perez, S. Cotillas, J. Llanos, P. Canizares, M.A. Rodrigo, Irradiation-assisted electrochemical processes for the removal of persistent organic pollutants from wastewater, Journal of Applied Electrochemistry, 45 (2015) 799-808.

[18] C. Saez, M.J. Martin de Vidales, P. Canizares, S. Cotillas, J. Llanos, J.F. Perez, M.A. Rodrigo, Irradiated Electrochemical Processes for the Removal of Persistent Organic Pollutants from Waters and Wastewaters, in: S. Palmas, M. Mascia, A. Vacca (Eds.) 10th Esee: European Symposium on Electrochemical Engineering, 2014, pp. 103-108.

[19] S.W. da Silva, C.R. Klauck, M.A. Siqueira, A.M. Bernardes, Degradation of the commercial surfactant nonylphenol ethoxylate by advanced oxidation processes, Journal of Hazardous Materials, 282 (2015) 241-248.

[20] F.C. Moreira, S. Garcia-Segura, V.J.P. Vilar, R.A.R. Boaventura, E. Brillas, Decolorization and mineralization of Sunset Yellow FCF azo dye by anodic oxidation, electro-Fenton, UVA photoelectro-Fenton and solar photoelectro-Fenton processes, Applied Catalysis B-Environmental, 142 (2013) 877-890.

[21] F. Li, G. Li, X. Zhang, Mechanism of enhanced removal of quinonic intermediates during electrochemical oxidation of Orange II under ultraviolet irradiation, Journal of Environmental Sciences-China, 26 (2014) 708-715.

[22] S. Xiao, Y. Song, Z. Tian, X. Tu, X. Hu, R. Liu, Enhanced mineralization of antibiotic berberine by the photoelectrochemical process in presence of chlorides and its optimization by response surface methodology, Environmental Earth Sciences, 73 (2015) 4947-4955.

[23] G.R.P. Malpass, D.W. Miwa, A.C.P. Miwa, S.A.S. Machado, A.J. Motheo, Photo-assisted electrochemical oxidation of atrazine on a commercial Ti/Ru0.3Ti0.7O2 DSA electrode, Environmental Science \& Technology, 41 (2007) 7120-7125.

[24] G.R.P. Malpass, D.W. Miwa, L. Gomes, E.B. Azevedo, W.F.D. Vilela, M.T. Fukunaga, J.R. Guimaraes, R. Bertazzoli, S.A.S. Machado, A.J. Motheo, Photo-assisted electrochemical degradation of the commercial herbicide atrazine, Water Science and Technology, 62 (2010) 27292736.

[25] F.d.L. Souza, C. Saez, P. Canizares, A.d.J. Motheo, M. Andres Rodrigo, Using a new photoreactor to promote conductive-diamond electrochemical oxidation of dimethyl phthalate, Journal of Chemical Technology and Biotechnology, 89 (2014) 1251-1258.

[26] E. Guinea, C. Arias, P.L. Cabot, J.A. Garrido, R.M. Rodriguez, F. Centellas, E. Brillas, Mineralization of salicylic acid in acidic aqueous medium by electrochemical advanced oxidation 
processes using platinum and boron-doped diamond as anode and cathodically generated hydrogen peroxide, Water Research, 42 (2008) 499-511.

[27] G. Hurwitz, P. Pornwongthong, S. Mahendra, E.M.V. Hoek, Degradation of phenol by synergistic chlorine-enhanced photo-assisted electrochemical oxidation, Chemical Engineering Journal, 240 (2014) 235-243.

[28] H. Bergmann, T. Iourtchouk, K. Schops, K. Bouzek, New UV irradiation and direct electrolysis - promising methods for water disinfection, Chemical Engineering Journal, 85 (2002) 111-117.

[29] R. Pelegrini, J. Reyes, N. Duran, P.P. Zamora, A.R. de Andrade, Photoelectrochemical degradation of lignin, Journal of Applied Electrochemistry, 30 (2000) 953-958.

[30] Y.J. Shih, K.H. Chen, Y.H. Huang, Mineralization of organic acids by the photoelectrochemical process in the presence of chloride ions, Journal of the Taiwan Institute of Chemical Engineers, 45 (2014) 962-966.

[31] E. Jurado, M. Fernandez-Serrano, J. Nunez-Olea, G. Luzon, M. Lechuga, Simplified spectrophotometric method using methylene blue for determining anionic surfactants: Applications to the study of primary biodegradation in aerobic screening tests, Chemosphere, 65 (2006) 278-285. [32] C.Trellu, E. Mousset, Y. Pechaud, D. Huguenot, E. D. van Hullebusch, G. Esposito, M.A. Oturan, Removal of hydrophobic organic pollutants from soil washing/flushing solutions: A critical review, Journal of Hazardous Materials, 306 (2016) 149-174.

[33] E.V. dos Santos, C. Saez, C.A. Martinez-Huitle, P. Canizares, M.A. Rodrigo, The role of particle size on the conductive diamond electrochemical oxidation of soil-washing effluent polluted with atrazine, Electrochemistry Communications, 55 (2015) 26-29.

[34] R. Lopez-Vizcaino, C. Saez, P. Canizares, M.A. Rodrigo, The use of a combined process of surfactant-aided soil washing and coagulation for PAH-contaminated soils treatment, Separation and Purification Technology, 88 (2012) 46-51.

[35] B. Louhichi, M.F. Ahmadi, N. Bensalah, A. Gadri, M.A. Rodrigo, Electrochemical degradation of an anionic surfactant on boron-doped diamond anodes, Journal of Hazardous Materials, 158 (2008) 430-437.

[36] C. Saez, R. Lopez-Vizcaino, P. Canizares, M.A. Rodrigo, Conductive-Diamond Electrochemical Oxidation of Surfactant-Aided Soil-Washing Effluents, Industrial \& Engineering Chemistry Research, 49 (2010) 9631-9635.

[37] E. Weiss, C. Saez, K. Groenen-Serrano, P. Canizares, A. Savall, M.A. Rodrigo, Electrochemical synthesis of peroxomonophosphate using boron-doped diamond anodes, Journal of Applied Electrochemistry, 38 (2008) 93-100.

[38] P. Canizares, F. Larrondo, J. Lobato, M.A. Rodrigo, C. Saez, Electrochemical synthesis of peroxodiphosphate using boron-doped diamond anodes, Journal of the Electrochemical Society, 152 (2005) D191-D196.

[39] K. Serrano, P.A. Michaud, C. Comninellis, A. Savall, Electrochemical preparation of peroxodisulfuric acid using boron doped diamond thin film electrodes, Electrochimica Acta, 48 (2002) 431-436.

[40] E. Weiss, K. Groenen-Serrano, A. Savall, Electrochemical mineralization of sodium dodecylbenzenesulfonate at boron doped diamond anodes, Journal of Applied Electrochemistry, 37 (2007) 1337-1344.

[41] S. Velazquez-Pena, C. Saez, P. Canizares, I. Linares-Hernandez, V. Martinez-Miranda, C. Barrera-Diaz, M.A. Rodrigo, Production of oxidants via electrolysis of carbonate solutions with conductive-diamond anodes, Chemical Engineering Journal, 230 (2013) 272-278.

[42] A. Sanchez, J. Llanos, C. Saez, P. Canizares, M.A. Rodrigo, On the applications of peroxodiphosphate produced by BDD-electrolyses, Chemical Engineering Journal, 233 (2013) 8-13. [43] Y.-T. Lin, C. Liang, J.-H. Chen, Feasibility study of ultraviolet activated persulfate oxidation of phenol, Chemosphere, 82 (2011) 1168-1172. 
[44] K. Hanna, S. Chiron, M.A. Oturan, Coupling enhanced water solubilization with cyclodextrin to indirect electrochemical treatment for pentachlorophenol contaminated soil remediation, Water Research 39 (2005) 2763-2773. 